\title{
O conceito de violência e a relação com os estágios da inteligência em crianças e adolescentes de diferentes contextos
}

\author{
Tamires Alves Monteiro 1 \\ Maria Thereza Costa Coelho de Souza ${ }^{2}$
}

\begin{abstract}
RESUMO
$\mathrm{O}$ artigo apresenta parte de um estudo evolutivo a respeito das ideias de crianças e adolescentes sobre violência, inseridos em diferentes contextos; fundamentado na teoria piagetiana e nas pesquisas referentes à construção do conhecimento social. Participaram da pesquisa 40 sujeitos entre 6 e 18 anos de idade. Apresentam-se os dados obtidos a partir do primeiro bloco de análise (definição de violência) a partir do segundo instrumento metodológico utilizado na pesquisa - entrevista clínica. Os resultados indicam que grande parte dos sujeitos da amostra não consegue retratar o fenômeno da violência em sua complexidade. Há uma tendência a associá-la somente à aspectos mais visíveis e concretos das situações ou conflitos retratados, concentrando-se no nível mais elementar de compreensão da realidade social.
\end{abstract}

PALAVRAS-CHAVE: Violência. Crenças. Jean Piaget. Epistemologia Genética.

The Concept of Violence and Relationship with the Stages of Intelligence in Children and Adolescents of Different Contexts

\begin{abstract}
The article presents part of an evolutionary study on the ideas of children and adolescents on violence, inserted at different based on Piagetian theory and research concerning the construction of social knowledge contexts. 40 subjects participated in the study between 6 and
\end{abstract}

\footnotetext{
${ }^{1}$ Mestre em Psicologia Escolar e do Desenvolvimento Humano. Instituto de Psicologia da Universidade de São Paulo, São Paulo, São Paulo, Brasil.E-mail: tamires.monteiro@usp.br

${ }^{2}$ Livre Docente. Instituto de Psicologia da Universidade de São Paulo, São Paulo, São Paulo, Brasil. E-mail: mtdesouza@usp.br
} 
18 years of age. Presents the data obtained from the first block of analysis (definition of violence) according to the second methodological instrument used in the research - clinical interview. The results indicate that most of the subjects fail to portray the phenomenon of violence in all its complexity. There is a tendency to associate it only the most visible and tangible aspects of the depicted situations or conflicts, focusing on the most basic level of understanding of social reality.

KEYWORDS: Violence. Beliefs. Jean Piaget. Genetic Epistemology.

$$
* * *
$$

\section{Introdução}

Neste artigo buscamos apresentar dados parciais de uma pesquisa que objetivou investigar a psicogênese da noção de violência em crianças e adolescentes, inseridos em diferentes contextos. Para tanto, partimos do referencial piagetiano a respeito da construção do conhecimento, das pesquisas que vem sendo desenvolvidas sobre a aquisição do conhecimento social e também de uma breve revisão na literatura a respeito do conceito de violência.

Diversos teóricos (MICHAUD, 1989; CANDAU, 2000; DERBARBIEUX; BLAYA, 2002) ao elegerem esse fenômeno como objeto de estudo enfatizam a complexidade em se atribuir um sentido exato ao termo. Destacando o quanto este fenômeno assume um caráter polissêmico e multifacetado.

Segundo Porto (2010), uma das dificuldades colocadas à reflexão sociológica sobre a violência se refere à sua construção enquanto objeto de estudos, pois a violência se caracteriza por ser um fenômeno empírico antes de ser um conceito teórico. Desta forma, um ponto referencial para a construção da violência enquanto conceito teórico seria a divisão deste fenômeno em diferentes tipos: violência física e violência simbólica. Isso porque a subjetividade que caracteriza os âmbitos moral ou simbólico não elimina o caráter de constrangimento dos atos agressivos aos sujeitos, mesmo na ausência de implicações físicas. Além dessa distinção entre 
violência física e simbólica é preciso considerar os sentidos e formas que a violência adquire em sua concretização.

É comum a palavra violência estar associada à ideia de força e/ou coação, no entanto, é preciso ser cuidadoso ao usar uma como sinônimo da outra. Afinal, nem toda ação que envolve o uso da força pode ser diretamente classificada como violenta. $\mathrm{O}$ que nos leva a seguinte questão: Em que momento o uso da força pode ser definido e visto como uma violência? Para responder a essa questão recorreremos novamente ao autor. Para Michaud (1989) são as normas e valores de uma determinada sociedade que define tal fato, ou seja, são os valores culturais e sociais que definirão quando uma força pode ou não ser compreendida como uma ação violenta. Portanto, tal como as normas e a cultura, a própria definição de violência deve sempre ser entendida como produto de um contexto social e histórico e, nesse sentido, nunca pode ser vista de forma universal e imutável.

A violência é algo que está intrinsicamente presente na nossa sociedade, que aflige e atinge tantos os adultos, como também as crianças e adolescentes, fazendo com que estes construam crenças e sentimentos sobre o fenômeno. Segundo dados da pesquisa de Waiselfisz (2011) 8 em cada 10 brasileiros têm muito medo de morrer assassinado e 7 em cada 10 de sofrer um assalto à mão armada. No que diz respeito às crianças, $42,7 \%$ de brasileiros entre 10 anos ou mais não se sentem seguros na cidade onde moram, 7,3\% das crianças brasileiras nessa faixa etária já foram vítimas de roubo ou furto e 1,6\% já sofreram alguma agressão física.

Nessa mesma pesquisa, o autor destaca que os jovens com idade entre 15 e 24 anos são as principais vítimas da violência. Entre os anos de 2008 a 2011, houve um aumento considerável de mortes dessa faixa etária da população, sendo que uma das principais causas foi o homicídio (39,7\%).

Diante desse contexto, sentimos a necessidade de pesquisar o que as crianças e os jovens pensam sobre este tema tão presente em nossa sociedade, assim o objetivo dessa pesquisa foi investigar quais eram as 
crenças que as crianças e adolescentes, inseridos em diferentes contextos, tinham a respeito da violência, como também analisar se haveria uma possível correspondência entre o conhecimento social e os estágios da inteligência.

\section{A Construção do Conhecimento Social numa Visão Interacionista}

Dentre os estudos psicogenéticos notamos que há alguns anos pesquisadores têm investigado como o sujeito pensa o mundo social. Estes trabalhos têm sido iniciados desde 1926, quando o epistemólogo Jean Piaget (1896 - 1980) se propôs a estudar as concepções infantis sobre o mundo. Em decorrência de suas obras sobre o assunto e as aberturas que elas proporcionaram, a partir da década de setenta do século passado, diversas pesquisas foram publicadas em diferentes países europeus e latinoamericanos.

No Brasil, um importante polo de pesquisa sobre a temática encontrase no Laboratório de Psicologia Genética da Universidade Estadual de Campinas (LPG/FE-UNICAMP), que desde 1994 vem estudando a construção do conhecimento social a partir de diferentes domínios desse conhecimento. É importante ressaltar que a ampliação desse campo de estudo, no Brasil, se deu, em grande parte, pelas contribuições advindas dos estudos de Juan Delval e sua equipe, na Espanha.

Tanto as pesquisas brasileiras, quantos as pesquisas internacionais vêm provando que a construção do mundo social é algo complexo que envolve tanto os aspectos físicos, quanto os cognitivos e sociais. Assim, os sujeitos constroem suas representações sobre o mundo a partir do rol de informações a que têm acesso, interpretando-as, reorganizando-as e reinventando-as a partir de um processo longo e criativo, que nada tem haver com uma simples cópia da realidade. É nesse processo de construção que o estágio de desenvolvimento cognitivo assume uma importância considerável no nível de compreensão do mundo social. 
As pesquisas sobre a temática numa abordagem piagetiana são um tanto recentes e datam do início dos anos 70 do século passado. Antes dessa época, os estudos sobre o conhecimento social, principalmente os primeiros estudos, tinham como foco a transmissão social e a pressão do ambiente como responsáveis pela formação das representações sociais. Para esta visão, as crianças absorviam as ideias vindas dos adultos e das pressões do ambiente sem ter um trabalho de elaboração e reinvenção dessas informações. Este ponto de vista serviu como base para trabalhos posteriores, como, por exemplo, a perspectiva de Durkheim que defendia a ideia de que era a pressão social (ou como dito por ele, a coação social) que determinava as representações sociais.

A partir dos anos 60, Serge Moscovici, apoiado nas ideias de Durkhein, traz a discussão de que as representações sociais são produto do conjunto de proposições, reações, avaliações e conhecimentos compartilhados pelos sujeitos de um determinado grupo social. A ideia principal, defendida por Moscovici, era de que as representações sociais eram um produto da sociedade, por isto, não podiam ser o resultado de uma construção individual.

De maneira geral podemos observar que essas diferentes abordagens se centram mais nos conteúdos do pensamento do indivíduo, buscando estabelecer relações de como essas representações vão permitindo sua socialização no seu meio social.

De acordo com Delval (2007), a construção de representações da realidade permite ao sujeito reconstruir em sua mente o mundo que o rodeia, e, por consequência, atuar e entender o meio em que vive. Diante disso, notamos que essa capacidade permite aos sujeitos não apenas dar sentido aos acontecimentos, mas também antecipar tais acontecimentos e atuar de acordo com essas representações.

O indivíduo ao longo do seu desenvolvimento constrói explicações bastante precisas sobre como funciona o mundo social. Para Delval (2007), as pessoas necessitam adquirir ideias sobre como está organizada a 
sociedade do ponto de vista econômico, político e das relações sociais para poderem atuar sobre ela. No entanto, não se pode chegar a essas ideias diretamente, é necessário construí-las por meio de um processo individual e lento.

Nesse sentido, os trabalhos de Delval (2007, 2002, 1989) mostram que as crianças não assimilam passivamente as informações que recebem do meio que as rodeia, mas realizam um trabalho árduo e gradual na construção do seu conhecimento e do conhecimento social.

Delval (2002) traz à tona a discussão sobre possíveis formas de organizar as diversas ideias que os sujeitos apresentam sobre a realidade. $\mathrm{O}$ autor levanta a hipótese de que as ideias que os sujeitos constroem sobre o mundo social têm um conjunto de traços comuns que se aplicam a diferentes domínios do conhecimento social, tais como as noções sobre direito, economia, escola, família etc. Assim, os sujeitos vão passando por diferentes formas de conceber a realidade. Tais formas seguem uma progressão em diferentes níveis, que podem ser compreendidos como uma maneira de ver e explicar a realidade.

No primeiro nível, as explicações são baseadas nos aspectos mais visíveis da situação, ou seja, em questões observáveis e não em processos ocultos que, muitas vezes, necessitam ser inferidos. Nesse nível as relações são vistas como pessoais e os sujeitos não reconhecem a existência de relações propriamente sociais, há ainda a dificuldade em se considerar a existência de conflitos.

O segundo nível caracteriza-se pelo início de consideração de aspectos não visíveis das situações, isto é, o sujeito começa a levar em conta processos inferidos a partir das informações de que dispõe. Aparece a distinção entre as relações pessoais e as institucionalizadas ou sociais. Os sujeitos desse nível percebem mais claramente os conflitos, "mas não conseguem encontrar soluções satisfatórias pela dificuldade de considerar aceitáveis os diferentes pontos de vista”. (DELVAL, 2002, p. 230).

No terceiro nível, os processos inferenciais ocupam um papel central 
nas explicações. A percepção dos conflitos é mais complexa e diferentes perspectivas e possibilidades são analisadas. A aplicação das regras sociais ocorre de uma maneira muito mais flexível.

A partir das discussões feitas no âmbito dos estudos sobre conhecimento encontra-se uma grande polêmica a respeito das semelhanças e diferenças entre conhecimento social e não social. Os problemas levantados que giram em torno dos níveis gerais de análise desses conhecimentos são: os processos implícitos na construção dos conhecimentos e as características dos objetos a conhecer.

De maneira geral, pode-se observar que alguns autores sustentam a ideia de que o conhecimento social é estruturalmente isomórfico ao conhecimento não social e que não cabe estabelecer uma distinção entre a esfera física e a social. Entre os adeptos dessa ideia estão Flavell (1985/1999), Jahoda (1984 apud Chakur, 2002), dentre outros.

Por outro lado, há estudiosos (FURTH, 1980; DAMON, 1979apud DELVAL, 1989; TURIEL, 1983, 1995) que buscam mostrar as diferenças entre esses conhecimentos, pautando-se na ideia de que essas se encontram na natureza, isto é, as formas de interações entre sujeito e objeto são diferentes. Pois, para o conhecimento social essas relações são permeadas por diversos componentes, tais como: afeto, arbitrariedade, história etc., elementos não existentes no domínio físico.

No âmbito das pesquisas brasileiras podemos destacar os estudos de Baptistella (2001), Borges (2001), Guimarães (2012) e Mano (2013), que tiveram como preocupação buscar uma relação entre os estágios do desenvolvimento cognitivo e os níveis de compreensão do mundo social propostos por Delval (2002). Os resultados dessas pesquisas demonstraram uma correspondência entre os conhecimentos lógico-matemático e social, defendendo a ideia de que, quanto mais elaborada é a estrutura cognitiva do sujeito, melhor será a sua compreensão sobre um determinado conteúdo do conhecimento social.

Segundo Delval (1989) as discussões a respeito das diferenças entre os 
tipos de conhecimento recaem sobre o problema das características do objeto a conhecer (físico ou social), da relação sujeito - objeto de conhecimento, dos processos cognitivos subjacentes e, por fim, nos mecanismos de aquisição do conhecimento.

Para Delval (1989), o conhecimento social e o não social se constroem da mesma forma, o que os diferencia são seus conteúdos, pois todos os conhecimentos têm suas peculiaridades e suas complexidades. No entanto, os processos e mecanismos que utilizamos para construir e conhecer determinado conhecimento são sempre os mesmos.

É importante destacar que embora estejamos partindo desse contexto mais amplo sobre a violência enquanto um conteúdo do conhecimento social, nosso objetivo no trabalho não será aprofundá-la, e sim estabelecer as possíveis relações entre o que a literatura tem a dizer sobre o fenômeno, o que nossos sujeitos pensam sobre ela e a construção dessas ideias a partir da visão de uma teoria do desenvolvimento. Considerando que nosso campo de estudo é a investigação da construção da noção de violência achamos válido trazer discussões sobre a sociogênese do fenômeno para assim analisarmos sua psicogênese.

\section{Método}

\section{Participantes}

Participaram desta pesquisa 40 sujeitos entre 06 e 18 anos de idade, de ambos os sexos, inseridos em diferentes ambientes. Sendo que uma parte desses alunos provenientes de instituições localizadas em bairros de baixo índice de violência e a outra parte oriundos de instituições localizadas em bairros de alto índice de violência.

Com base na obra de Delval (2002), os sujeitos foram divididos da seguinte forma: 10 sujeitos de 06 anos; 10 de 10 anos; 10 de 14 anos e 10 de 18 anos. A escolha dos locais para a coleta de dados foi feita a partir da 
análise de dados estatísticos sobre o índice de criminalidade das regiões da cidade de São Paulo. Tais dados foram consultados por meio de pesquisas estatísticas realizadas pelo site da segurança pública do Estado de São Paulo.

Assim, de acordo com os dados apresentados por este site, entre os meses de janeiro a maio do ano de 2011, a região do Belém, localizada na zona leste da cidade de São Paulo, foi considerada a que possui o menor índice de criminalidade e a região da Sé e Centro a que possui o maior índice.

Para uma melhor visualização da distribuição dos sujeitos por idade e contexto, apresentaremos a figura a seguir.

FIGURA 1: Distribuição dos sujeitos por idade e contexto

\begin{tabular}{|c|c|c|}
\hline Idade & Alto Índice de Violência & $\begin{array}{c}\text { Baixo Índice de } \\
\text { Violência }\end{array}$ \\
\hline 6 & 5 & 5 \\
\hline 10 & 5 & 5 \\
\hline 14 & 5 & 5 \\
\hline 18 & 5 & 5 \\
\hline
\end{tabular}

Fonte: Monteiro, 2013

\section{Instrumentos}

Os participantes foram submetidos, individualmente, a três instrumentos metodológicos diferentes, sendo o primeiro provaspiagetianas para o diagnóstico operatório,que pudessem verificar os estágios de desenvolvimento do pré-operatório até o operatório formal. As provas escolhidas foram: operações de permutações, avaliando à noção de acaso; oscilações do pêndulo, em relação à identidade (PAULI et. al., 1981).A justificativa para a aplicação deste instrumento foi analisar em que estágio de desenvolvimento intelectual os sujeitos eram classificados, bem como 
verificar se um sujeito que constitui uma estrutura operatória possuía uma noção mais elaborada do conhecimento social, mais especificamente, da noção de violência.

Após a aplicação das provas piagetianas os sujeitos foram convidados a participarem de uma entrevista semiestruturada com questões que tiveram como temática a violência. $\mathrm{O}$ objetivo do uso deste instrumento foi analisar como os sujeitos percebem a violência, suas causas e soluções.

Esse instrumento foi elaborado com base em metodologia utilizada em estudo anterior (MONTEIRO, 2010). A entrevista (clinica) foi composta da seguinte forma: 1) Você já ouviu falar de violência? O que acha que é violência? 2 ) Você já viu alguma violência? Se sim, qual e onde? 3) O que você acha da violência? Por que você acha isso? 4) Você acha que existe só uma violência ou tem mais? Se sim, qual e por quê? 5) Você acha que alguma violência é mais grave? Qual? Por quê? 6) Quem você acha que faz a violência? 7) Por que será que a violência existe? 8) Será que tem um jeito de acabar com ela?

O terceiro instrumento foi o curta-metragem "Jonas e Lisa" da coletânea "Direitos do Coração" (COTÈ; SCHORR, 2006). Esta coletânea é composta por uma série de curtas-metragens, em formato de desenho animado, que contam diversas e diferentes histórias que envolvem a violação dos direitos humanos. O curta-metragem escolhido "Jonas e Lisa" tem a duração de dez minutos e apresenta, em formato de desenho animado sem falas, a história de duas crianças e um bebê que vivem em um morro carioca e que passam por diversos tipos de violência, desde a pobreza até o trabalho infantil. O objetivo do uso desse instrumento foi analisar como os sujeitos interpretam esse filme e se conseguiam perceber os vários tipos de violência ali contidos.

É importante ressaltar que optamos por esta sequência de aplicação dos instrumentos metodológicos, seguindo os pressupostos do método-clínico crítico Piagetiano (PIAGET, 1926/1979). Nesse sentido, com o primeiro instrumento buscamos ter uma ideia de qual era a estrutura operatória de 
pensamento do sujeito entrevistado. Já com o segundo instrumento (entrevista clínica), buscamos encontrar as crenças espontâneas a respeito da noção da violência e por fim com o terceiro instrumento (curta-metragem) tivemos como objetivo localizar as crenças desencadeadas nesses sujeitos.

\section{Procedimentos para Coleta de Dados}

Os instrumentos metodológicos foram aplicados pela pesquisadora na escola do aluno, individualmente, e todo o diálogo estabelecido com o experimentador foi gravado em áudio e vídeo, para posteriormente ser transcrito e analisado.

As provas piagetianas foram aplicadas inicialmente para o diagnóstico do pensamento operatório (operações de permutações, oscilações do pêndulo e conservação do volume). Num segundo momento os sujeitos foram convidados a responder questões numa entrevista semiestruturada. Em seguida, apresentamos aos sujeitos um curta-metragem que foi exibido no computador; depois de assistir ao filme os sujeitos foram questionados sobre o que viram, o que os agradou ou não, além de serem perguntados, diretamente, se no vídeo havia algum tipo de violência.

\section{Análise dos Dados}

Após a coleta de dados, as respostas dos participantes foram transcritas na íntegra e analisadas quantitativa e qualitativamente. A análise qualitativa se deu por meio da construção de categorias de respostas. No caso das entrevistas, primeiramente foram criados eixos temáticos que agruparam questões tratando do mesmo aspecto e posteriormente foram estabelecidas as categorias. Já para o curta-metragem, as respostas foram agrupadas somente em categorias.

Essas categorias foram elaboradas a partir das respostas dos sujeitos e eram definidas conforme a frequência e a regularidade com que apareciam, 
indicando, portanto, uma crença desencadeada ou espontânea que os entrevistados tinham sobre a questão. Assim, quando uma crença aparecia algumas vezes, considerávamos como uma categoria de resposta. Posteriormente, as categorias foram interpretadas de acordo com os níveis de compreensão da realidade social, conforme proposto por Delval (2002).

Por fim, os dados foram tabulados e analisados estatisticamente por meio do pacote estatístico "SPSS versão 16.0 for Windows". Assim, para as variáveis contínuas, realizamos o teste de normalidade de KolmogorovSmirnov, sendo que para variáveis com distribuição normal realizamos os testes paramétricos $\mathrm{t}$ de Student e para variáveis sem distribuição normal utilizamos os testes não paramétricos de Kruskal-Wallis.Comparamos os sujeitos quanto à idade em relação à classificação nas provas piagetianas, entrevista clínica, curta-metragem e contexto. Além disso, também comparamos os sujeitos quanto às provas piagetianas e a entrevista clínica.

É importante destacar que adotamos o nível de significância de $5 \%$ $(0,050)$ para a aplicação dos testes estatísticos.

A seguir apresentaremos a análise e os resultados dos dados referentes ao primeiro eixo temático - Definição de violência, da entrevista clínica, objetivo deste artigo.

\section{Resultados e Discussão}

\section{Eixo Temático - Definição de Violência}

Neste eixo buscamos analisar como os sujeitos definiam violência. As perguntas que foram agrupadas nesse eixo são: "Você já ouviu falar de violência? O que acha que é violência?”; “Você já viu alguma violência? Se sim, qual e onde?" e "Você acha que existe só uma violência ou tem mais? Se sim, qual e por quê?".

Categoria 1 - Ações isoladas 
As respostas que correspondem a esta categoria relacionam a violência como agressões físicas, como brigar e bater, ao bullying quando o relacionavam as ações isoladas, tais como: agressões físicas e verbais. Nesta categoria também foram incluídos os atos criminosos, como, por exemplo, roubar, matar, estuprar etc. As respostas desse tipo foram as mais apresentadas, aparecendo nas diversas idades. Conforme pode ser visto no exemplo a seguir:

LIS $(7 ; 4) \mathbf{a}^{3} \mathrm{E}$ o que você acha que é violência? Acho que é agredir as pessoas. Agredir? E como que a gente agride as pessoas? Quando... Assim, você enche o saco da outra pessoa. E ai quando você fica em cima, ela também enche o seu. Como que é "encher o saco"? É quando você... Obriga a fazer uma coisa ai a outra briga com você [...]

Categoria 2 - Ações que envolvem diferentes fatores e questões sociais mais amplas

Nas respostas desta categoria, percebemos que os sujeitos acreditam que a violência está relacionada ao tráfico e uso de drogas lícitas ou ilícitas, pessoas morando na rua, preconceito, violência política, como, por exemplo, a corrupção etc. Conforme ilustra o exemplo a seguir:

GAS (14; 3)bE para você o que é violência? Violência é um tema muito amplo. Mas se você fosse nomear, o que seria a violência? Falta de segurança. Mais coisas? Falta de consciência da própria pessoa que muitas vezes se coloca no meio da própria violência, o lugar onde vive, se ocorrem muitos assassinatos, muitas brigas. [...] Você acha que tem uma violência ou tem mais? Não, tem mais. Você consegue me falar algumas?Bullying, violência doméstica, o

\footnotetext{
${ }^{3} \mathrm{~A}$ identificação dos sujeitos foi apresentada conforme o método clínico-crítico piagetiano. Assim, apresentamos, primeiramente, as iniciais do nome dos participantes, logo em seguida, entre parênteses, há a idade em anos e meses e, por fim, a instituição a qual os sujeitos pertencem. Assim, as letras a e b representam as instituições localizadas em ambientes de baixo índice de violência e as letras c e d as localizadas num local de alto índice.
} 
assédio moral que vem a ser uma violência, o preconceito é uma violência contra a autoestima da pessoa.

Categoria 3 - Tudo que fere o outro (fisicamente e psicologicamente)

Nesta categoria foram agrupadas as resposta em que os sujeitos relacionavam a violência com tudo àquilo que pode ferir, tanto psicológica e/ou fisicamente, uma pessoa. Aqui também foi enquadrado o caso do bullying, quando os sujeitos sabiam explicar corretamente o que era o fenômeno. Vejamos alguns exemplos:

GAB $(17 ; 2) b$ Eu quero que você fale pra mim o que você acha que é violência? Violência na minha opinião? Isso, o que você pensa sobre isso? Acredito que violência não venha a ser todo tipo de agressão, toda violência é uma agressão. Porém violência é um atentado a uma outra pessoa. E que tipo "atentado"? Suponhamos, pichar a parede não é violento, é vandalismo, porém se picham a parede da sua casa você acha que de alguma maneira invadiram seu espaço, e esses que invadiram seu espaço estão sendo violentos e não têm punição. Vou explicar... Formular aqui sua resposta. Toda uma ação direcionada ao outro que não está ciente causa um desconforto.

\section{Categoria 4 - Outros}

Nesta categoria foram enquadradas as respostas pouco frequentes que os sujeitos davam ao falarem o que era violência. Conforme pode ser visto no exemplo a seguir:

REN (6; 7)c O que você imagina que seja violência? Eu imagino que seja mau amor pelos outros. O mau amor pelos outros? Como assim? Assim, se a gente gosta de uma pessoa a gente tem amor por ela, se a gente não gosta, a gente tem malcriação por ela. E o que é a violência em si? Eu acho que é a violência em si é a 
malcriação pelas pessoas. Como que a gente faz malcriação? Que nem assim, a minha mãe fala: "REN vai tomar banho." Ai eu falo: "Eu não quero mãe.” Ai isso chama malcriação.

$\mathrm{Na}$ tabela e na figura a seguir encontram-se os dados referentes à quantidade de sujeitos inseridos em cada categoria de respostas e contexto social.

TABELA 1: Distribuição dos sujeitos nas categorias de respostas do eixo definição de violência

\begin{tabular}{|c|c|c|c|c|c|}
\hline \multirow[t]{2}{*}{ Categorias de Respostas } & \multicolumn{4}{|c|}{ Idade } & \multirow[t]{2}{*}{$\%$} \\
\hline & 06 & 10 & 14 & 18 & \\
\hline Categoria 1 - Ações Isoladas & 10 & 10 & 9 & 1 & $61,2 \%$ \\
\hline $\begin{array}{c}\text { Categoria } 2 \text {-Ações que envolvem } \\
\text { diferentes fatores e questões sociais } \\
\text { mais amplas }\end{array}$ & - & 1 & 2 & 5 & $16,3 \%$ \\
\hline $\begin{array}{c}\text { Categoria } 3 \text { - Tudo que fere o outro, } \\
\text { física e psicologicamente }\end{array}$ & - & - & 3 & 7 & $20,4 \%$ \\
\hline Categoria $4-$ Outros & 1 & - & - & - & $2,1 \%$ \\
\hline TOTAL & 11 & 11 & 14 & 13 & $100 \%$ \\
\hline
\end{tabular}

FIGURA 2: Distribuição dos sujeitos nas categorias de respostas e contexto social do eixo definição de violência

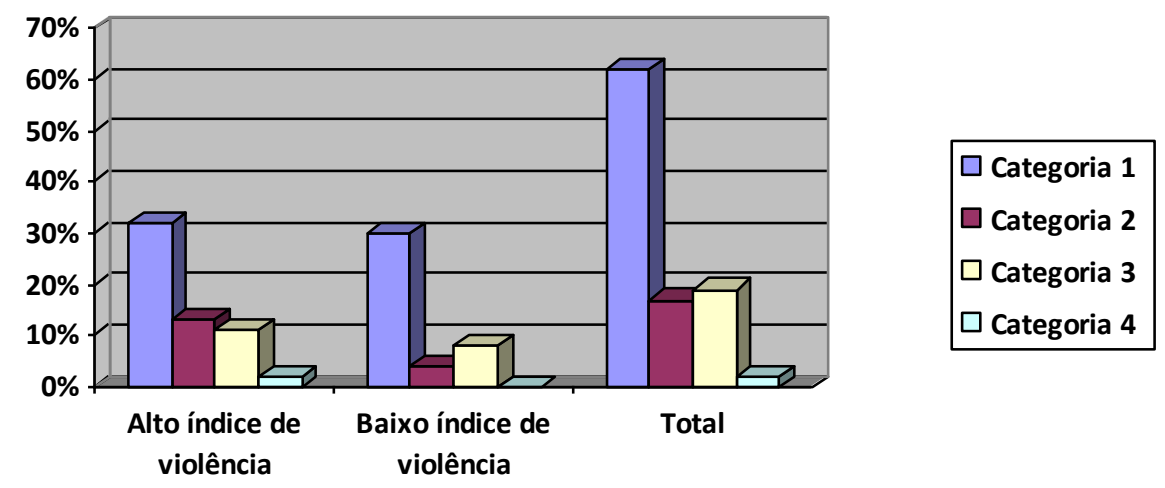

Fonte: Monteiro, 2013.

Ao analisarmos a tabela 1 podemos perceber que as respostas que se enquadram na categoria 1 são as mais mencionada pelos sujeitos de todas as 
idades. A partir desse dado evidenciamos o quanto o fenômeno da violência ainda é pouco compreendido pelas crianças e adolescentes. Estes ficam somente numa análise mais superficial e perceptível sobre a temática, demonstrando a dificuldade que estes têm de compreender o fenômeno da violência e sua complexidade, como aponta os estudos de Michaud (1989), Candau (2000) e Porto (2010).

Conforme pode ser observado na tabela 1 somente os sujeitos mais velhos (14 a 18 anos de idade) foram enquadrados na categoria 3. Estes sujeitos conseguiram ampliar suas ideias a respeito do fenômeno, demonstrando considerar outros aspectos mais abstratos e menos perceptíveis da violência.

Ao observamos a figura 1, vemos que a distribuição dos sujeitos inseridos em diferentes contextos é bem próxima, evidenciando que não há grandes diferenças entre as crenças desses sujeitos em decorrência dos locais que estão inseridos. No entanto, apesar de haver semelhanças entre as respostas destes, notamos que os sujeitos inseridos em instituições localizadas em regiões com alto índice de violência foram que deram mais respostas que poderiam ser enquadradas em diversas categorias.

Tal dado nos faz pensar que a exposição maior a essas situações faz com que o sujeito amplie seu repertório de ideias a respeito do fenômeno, todavia, sabemos que a qualidade dessas ideias não depende unicamente de uma maior exposição a esse fenômeno, mas das experiência significativas que se tem com o objeto, assim como os conteúdos afetivos, sociais e morais que o sujeito constrói em relação a violência.

A fim de enquadrarmos os sujeitos dentro dos níveis de compreensão da realidade social, todo o protocolo da entrevista clínica era lido, interpretado e analisado conforme as características dos níveis segundo Delval (2002), apresentadas no decorrer desse trabalho. Com intuito de oferecermos uma melhor visualização da distribuição dos sujeitos dentro dos níveis de compreensão, apresentaremos a seguir a tabela 2 . 
TABELA 2: Distribuição dos sujeitos por nivéis de compreensão da realidade social na entrevista clínica

\begin{tabular}{cccccc}
\hline $\begin{array}{c}\text { Nível de Compreensão da } \\
\text { Realidade Social }\end{array}$ & 06 & 10 & 14 & 18 & $\%$ \\
\hline Nível I & 10 & 10 & 7 & 1 & $70 \%$ \\
\hline Nível II & - & - & 3 & 6 & $22,5 \%$ \\
\hline Nível III & - & - & - & 3 & $7,5 \%$ \\
\hline Total & 10 & 10 & 10 & 10 & $100 \%$ \\
\hline
\end{tabular}

Fonte: Monteiro, 2013.

Como podemos observar a partir da tabela 2, a maioria dos sujeitos participantes concentram-se no nível mais elementar da compreensão do conhecimento social, mesmo os sujeitos mais velhos, como os de 14 anos de idade. Segundo Delval (2002), os sujeitos pertencentes a este nível possuem explicações simplistas sobre o mundo social. Estas explicações se baseiam nas aparências, naquilo que há mais de concreto e perceptível. Nesse sentido, os sujeitos enquadrados nesse nível acreditam que a violência está relacionada às questões mais concretas, assim a denominam como sendo: bater, roubar, matar, brigar etc.

$\mathrm{Na}$ busca de uma relação entre o conhecimento social e os estágios da inteligência, notamos que as respostas deste primeiro nível revelam a presença de um pensamento egocêntrico. Segundo Piaget (1965/1973), o sujeito nesse estágio vê a realidade a partir do seu ponto de vista porque é regulado pelo egocentrismo. Nesse sentido, estes têm dificuldade em considerar o outro, por isso, não consideram os diversos aspectos da realidade que os cercam, nesse caso, os diversos aspectos que compõem o fenômeno da violência. Portanto, por estarem num momento em que o egocentrismo se faz tão presente, não conseguem explicar a realidade tal como ela é, limitando-se a caracterizá-la e descrevê-la como a veem.

Em relação ao nível II de compreensão da realidade social, os sujeitos pertencentes a este nível começam a ver o mundo social como algo em 
transformação. Todavia, apesar das respostas dos sujeitos serem mais elaboradas, ainda se caracterizam por justificativas elementares, que são manifestadas de forma confusa. As explicações próprias desse nível refletem a grande dificuldade que os sujeitos apresentam para considerar os distintos elementos envolvidos no processo de compreensão do mundo social. Por esse motivo, as explicações são variadas e mais amplas que as do nível anterior, no entanto, suas justificativas ora retornam a argumentos no nível I, ora buscam uma articulação mais coerente, mas sem atingir a elaboração própria do nível III, demonstrando assim um período de transição.

Delval (2002) afirma que as explicações decorrentes desse segundo nível não só são encontradas nas crianças e adolescente, mas podem também ser vistas em alguns adultos, o que pode ser observado no nosso estudo, considerando que grande parte dos adolescentes na faixa de 18 e 19 anos de idade concentram־se nesse nível.

Os sujeitos classificados nesse segundo nível começam a ver a violência com algo mais amplo, envolvendo questões de ordem social e moral, tais como: O uso e o tráfico de drogas, pessoas morando na rua, preconceito etc. Embora apresentam características mais sofisticadas para denominarem o que é violência, como, por exemplo, o preconceito, ao falarem sobre ela, seus argumentos muitas vezes são pobres e um tanto estereotipados.

Ao recorrermos à teoria piagetiana para explicar esse momento, podemos perceber semelhanças com o estágio operatório concreto. Visto que nesse estágio os sujeitos passam pelo processo de descentração, isto é, deixam de lado o egocentrismo e começam a levar em conta os outros pontos de vista. Este fato faz que o sujeito consiga organizar um número cada vez maior de situações, dando a suas explicações uma forma mais objetiva; entretanto, permanecem presos a situações concretas.

As respostas enquadradas no nível III de compreensão demonstram que os sujeitos, em suas explicações, parecem buscar uma relação entre os fatos observados e as informações que recebem, seja pela mídia, seja pela escola, seja no cotidiano de suas vidas, levando em consideração inclusive os 
aspectos mais abstratos.

As explicações enquadradas no nível III, interpretadas a partir da teoria piagetiana, revelam que, com a conquista do pensamento formal, o sujeito tem possibilidade de compreender as noções sociais em toda a sua amplitude, uma vez que eles são capazes de coordenar diferentes pontos de vista e basear suas explicações sobre enunciados verbais, ou seja, de hipóteses.

Os sujeitos pertencentes a este nível relacionam a violência não só a algo físico, mas também a aspectos psicológicos, ou seja, a violência passa a ser vista como aquilo que fere o outro, seja física ou psicologicamente. Além disso, a violência também é relacionada a questões sociais, tais como: pobreza, desigualdade social, preconceito, corrupção, etc; acompanhadas de argumentos mais realistas que abordam a complexidade do tema.

A seguir encontra-se uma tabela com os resultados obtidos por meio do teste estatístico em relação ao estágio cognitivo e os níveis de compreensão da realidade social na entrevista clínica.

TABELA 3: Resultados da aplicação do teste Krusal-Wallis para níveis de compreensão da realidade social na entrevista clínica e estágio de desenvolvimento cognitivo

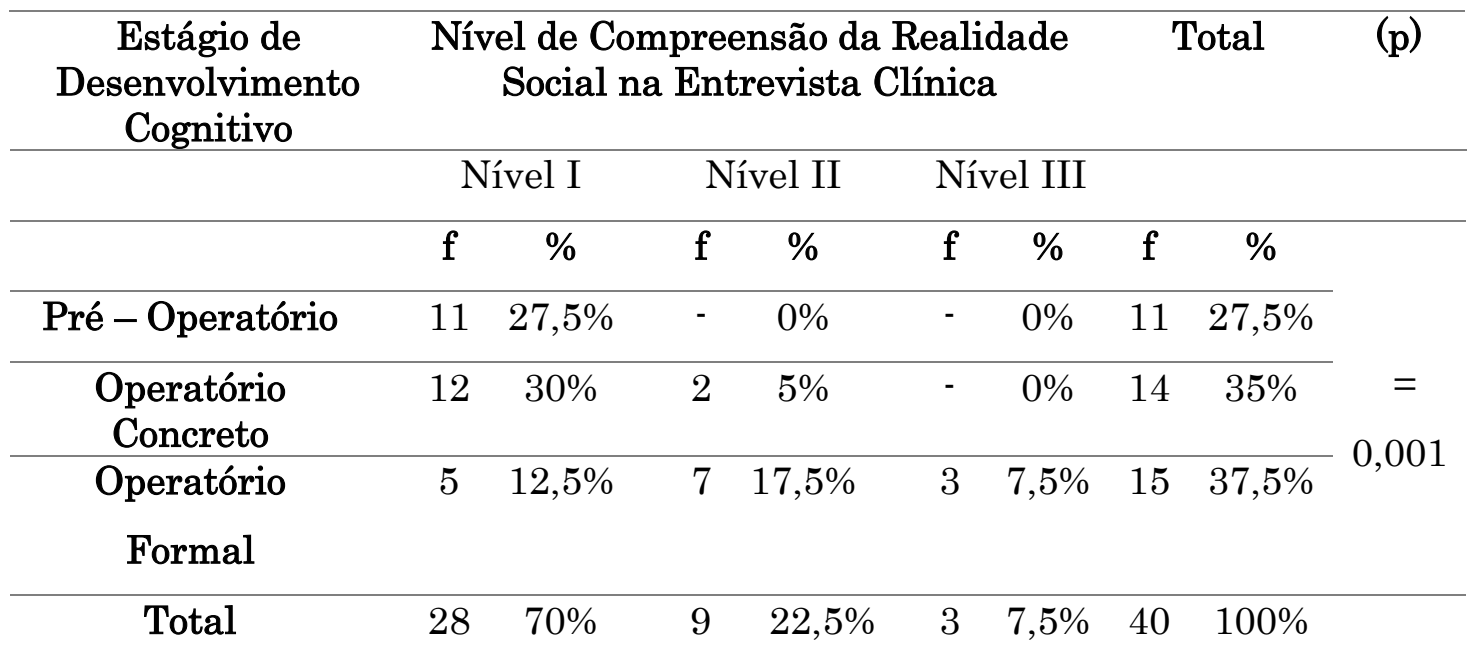

Fonte: Monteiro, 2013.

$\mathrm{Na}$ busca por uma correlação entre o estágio de desenvolvimento 
cognitivo e os níveis de compreensão da realidade social na entrevista clínica foi possível observar, por meio do teste Kruskal-Wallis, uma diferença estatisticamente significativa $\left(x^{2}=18,754 ; p=0,001\right)$. Demonstrando que há uma estreita correspondência entre os níveis de compreensão da realidade social na entrevista clínica e os estágios da inteligência. Assim, podemos dizer que os níveis de compreensão mais elaborados do mundo social são acompanhados por estágios mais avançados do desenvolvimento cognitivo, como demonstram os estudos de Delval (1989), Baptistella (2001), Borges (2001), Guimarães (2012) e Mano (2013).

É importante ressaltar que a passagem de um nível ao outro não ocorre de forma direta e mecânica, mas é fruto de um longo processo de interação com o meio social. Em que implica num processo amplo de desequilíbrios contínuos, de assimilações e acomodações. Para construir essa compreensão, o sujeito precisa realizar e passar pelas as várias etapas da abstração reflexionante e também da tomada de consciência, isto é, conseguir coordenar as ações que realiza sobre os fenômenos da realidade social.

Após a análise dos resultados, notamos que há entre as diversas respostas fornecidas pelos sujeitos uma organização complexa e evolutiva, seguindo um caminho bem semelhante ao estudo de Monteiro (2010) e outras pesquisas que tiveram como intuito investigar as noções sociais.

A respeito da relação entre os níveis de compreensão da realidade social na entrevista e o contexto social, de acordo com os resultados do teste Krusal-Wallis não houve diferença estatística significante $\left(\mathrm{x}^{2}=3,254 ; \mathrm{p}>\right.$ 0,05). Tal dado demonstra que o contexto social no qual os sujeitos participantes pertenciam não influenciava no tipo e na qualidade das respostas que os sujeitos davam ao pensar na violência (tanto estruralmente, quanto em conteúdo).

\section{Considerações Finais}

A partir dos dados apresentados foi possível evidenciar que as 
respostas que os sujeitos dão em relação às questões sobre a violência não se limitam a uma simples reprodução de informações e, muito menos, são cópias da realidade, mas o resultado de um processo criativo e ativo do sujeito. Além disso, percebemos que tais ideias e o processo de construção sobre o tema são, em muitos aspectos, coincidentes com a própria evolução do termo apresentada pela literatura. Nessa evolução, percebe-se as dificuldades e as necessidades de inserção de novos elementos e novos enfoques para a definição e interpretação sobre o fenômeno da violência.

A fim de verificar a existência de uma correspondência entre os níveis de compreensão da realidade social e os estágios do desenvolvimento cognitivo, partimos da hipótese de que compreensões mais elaboradas do mundo social, no caso da nossa pesquisa, a noção de violência, são pautadas em estruturas cognitivas mais sofisticadas. A partir do teste Kruskal-Wallis encontramos uma relação estatisticamente significativa, isto é, nossa hipótese foi comprovada.

Apesar de nossa hipótese ter sido comprovada, um dado nos chamou a atenção: somente $7,5 \%$ dos sujeitos da nossa amostra alcançaram o nível mais elevado da compreensão do mundo social. Grande parte dos nossos sujeitos se concentraram nos níveis mais elementares. Este dado evidencia que tanto as crianças, quanto os adolescentes possuem uma visão muito simplista sobre a violência e, consequentemente, não conseguem perceber e compreender a complexidade do tema. Além disso, notamos que o fenômeno da violência não é visto por esses sujeitos como um material para a reflexão, assim muitos ficam presos à ideias imediatistas e concretas e, muitas vezes, pautadas no senso comum. Adotando o referencial piagetiano podemos dizer que esses sujeitos não conseguem atingir os níveis mais superiores das abstrações e, por consequência, não chegam a uma tomada de consciência sobre o assunto.

Este dado também nos permite inferir que as estruturas cognitivas são uma condição necessária e extremamente importante para a construção e compreensão das noções sociais, no entanto, não são suficientes. As 
experiências significativas com o objeto de conhecimento, os conteúdos afetivos, sociais e morais que o sujeito tem com este objeto de conhecimento também têm uma grande relevância.

Assim, todos os progressos evolutivos em relação a noção de violência não são determinados unicamente pelo acesso a uma maior quantidade de informações que o sujeito recebe conforme avança em seu desenvolvimento, mas deve-se ao fato de como essas informações vão sendo incorporadas pelo sujeito e como ele vai dando significado a elas. Isto é, como o sujeito ao longo da sua interação com este objeto de conhecimento vai assimilando e acomodando essas informações e com isto buscando e realizando abstrações cada vez mais potentes e complexas até chegar numa tomada de consciência sobre essas questões.

Uma das questões que nos preocupa é em relação a compreensão elementar e pobre dos fenômenos do mundo social que nossos adolescentes possuem. Quando comparamos as pesquisas psicogenéticas brasileiras com as internacionais notamos que nossos jovens possuem uma visão muito simplista de alguns contéudos da realidade social (CANTELLI, 2000; PIECZARKA, 2009; MONTEIRO, 2010; MANO, 2013). Dessa forma, acreditamos ser importante que haja outras investigações com diferentes conteúdos do mundo social, para que se confirmem ou não esse fato, além de buscarem explicações para isto. Caso esse dado se confirme é necessário pensarmos: O que pode ser feito para solucionar tal problema? Será que nossas escolas e outras instituições responsavéis pela formação dos sujeitos têm um papel relevante e importante nesse processo? Acreditamos que sim.

Notamos o quanto a escola está preocupada em informar seus alunos sobre um fenômeno que apesar de não ser recente tem ganhado muito destaque ultimamente. No entanto, apesar da boa intenção, a escola acaba fazendo um trabalho sem muito sentido, pois tem como ideia que somente a transmissão daria conta da conscientização de seus alunos para com o fenômeno.

Sabemos que somente esclarecer o tema com os alunos não é suficiente 
para minimizar e/ou erradicar a violência como um todo, mas é preciso que a escola vá além da transmissão, que tenha a preocupação de discutir com seus alunos sobre essas questões, que eles possam, acima de tudo, serem ouvidos e a partir das suas ideias buscarem um trabalho de conscientização.

Defendemos a ideia de que seja necessário um trabalho adequado em relação ao conhecimento social. Os conteúdos deste tipo de conhecimento necessitam de um trabalho semelhante aos dos outros tipos de conhecimentos (físico e lógico-matemático). Sendo assim, a construção das noções sociais não pode ficar restrita somente a transmissão social, é preciso que nossas crianças e adolescentes experimentem e vivenciem atividades que os levem a refletir sobre os fenômenos sociais, que possam agir, debater e trocar experiências sobre isso, isto é, é necessário que haja uma experimentação ativa do sujeito, informações adequadas e reflexões para além da prática para a construção das noções sociais. Em síntese, o processo pode ser entendido como partindo de um saber fazer para uma compreensão cada vez mais elaborada do processo.

Dessa forma, é essencial que o educador conheça como seu aluno se desenvolve e aprende, além de ter conhecimento do quanto é importante ter um ambiente solicitador, cooperativo e livre de pressões e sanções expiatórias, pois só assim ele consiguirá desenvolver atividades e estratégias de ensino que possibilitem uma aprendizagem significativa e de qualidade, como também um espaço cada vez mais democrático e propício para o desenvolvimento integral do sujeito.

\section{Referências}

BAPTISTELLA, E. C. F. A compreensão de um conteúdo de um comercial televisivo na infância. 2001. 225 f. Dissertação (Mestrado em Educação) - Faculdade de Educação, Universidade Estadual de Campinas, Campinas, 2001.

BORGES, R. R.A construção da noção de família em crianças pré-escolares. 2001. 204 f. Dissertação (Mestrado em educação) - Faculdade de Educação, Universidade Estadual de Campinas, Campinas, 2001.

CANDAU, V. M. Direitos humanos, violência e cotidiano escolar. In: CANDAU, V. 
M. (org.). Reiventar a escolar. Petrópolis/RJ: Vozes, p. 137-166, 2000.

CANTELLI, V. C. B. Um estudo psicogenético sobre as representações de escola em crianças e adolescentes. 2000. 243 f. Dissertação (Mestrado em Educação) Faculdade de Educação, Universidade Estadual de Campinas, Campinas, 2000.

CHAKUR, C. R. S. L. O social e o lógico-matemático na mente infantil. cognição, valores e representações ideológicas. São Paulo: Arte \& Ciência, 2002.

COTÉ, Z.; SCHORR, D. Jonas e Lisa. In: Pierre Trudeau (direção). Direitos do Coração. Brasil: Paulinas, 2006. DVD.

DEBARBIEUX, E.; BLAYA, C. Violência nas escolas e politicas públicas. (Relatório de pesquisa). Brasília: UNESCO. Disponível em: http://unesdoc.unesco.org/images/0012/001287/128720por.pdf. Acesso em: 10 jul. 2017.

DELVAL, J. La representación infantil del mundo social In: TURIEL, E.; ENESCO, L.; LINAZA, J. (Comps). El mundo social e la mente del niño. Madrid: Alianza, 1989 .

Introdução à prática do método clínico: descobrindo o pensamento da criança. Tradução de Fátima Murad. Porto Alegre: Artmed, 2002.

Aspectos de la construcción del conocimiento sobre la sociedad. Educar em revista, n. 30, p. 45-64, 2007.

FLAVELL, J. et. al. Desenvolvimento cognitivo. Tradução de Claúdia Dornelles. 3. ed., Porto Alegre: Artmed, [1985], 1999.

GUIMARÃES, T. Intervenção pedagógica e noções sobre o meio ambiente: a construção do conhecimento social à luz da epistemologia genética. 2012. $221 \mathrm{f}$. Dissertação (Mestrado em educação) - Faculdade de Ciências e Filosofia, Universidade Estadual Paulista, Marília, 2012.

MANO, A. M. P. Ideias de estudantes sobre a origem da Terra e da vida e suas relaçôes com o desenvolvimento cognitivo: um estudo psicogenético. 2013. $171 \mathrm{f}$. Dissertação (Mestrado em educação) - Faculdade de Ciências e Filosofia, Universidade Estadual Paulista, Marília, 2013.

MICHAUD, Y. A violência. São Paulo: Ática, 1989.

MONTEIRO, T. Um estudo evolutivo sobre as ideias de crianças e adolescentes a respeito da violência urbana. 2010. $222 \mathrm{f}$. Trabalho de conclusão de curso de Pedagogia (Licenciatura em Pedagogia)- Faculdade de Ciências e Filosofia, Universidade Estadual Paulista, Marília, 2010.

PAULI, L. et. al. Inventários de Jean Piaget. Lisboa: Estampa, 1981.

PIAGET, J. Estudos sociológicos. Tradução de Agnes Cretella. Rio de Janeiro: 
Forense, [1965], 1973.

A representação do mundo na criança. Tradução de R. Fiúza. Rio de Janeiro: Record, [1926], 1979.

PIECZARKA. T. Concepção de desigualdade social e mobilidade socioeconômica de adolescentes de escola pública de Curitiba. 2009. 257 f. Dissertação (Mestrado em educação) - Faculdade de Educação, Universidade Federal do Paraná, Curitiba, 2009.

PORTO, M. S. G. A violência entre o fenômeno e o conceito: possibilidades e limites de definição. IN: PORTO, M. S. G. (org.). Sociologia da violência: do conceito às representações sociais. Brasília: Editora Francis, 2010.

TURIEL, E. The development of social knowledge morality an convention. New York: Cambridge University Press, 1983.

TURIEL, E. Interaction and development social cognition. In: HIGGINS, E. T.; RUBLE, D. N.; HARTUP, W. W. (eds.). Social cognition and social development: a sociocultural perspective. Cambridge: Press, p. 333 -355, 1995.

WAISELFISZ, J. J. O mapa da violência de 2011: os jovens do Brasil. Brasília: UNESCO, Instituto Sangari, Ministério da Justiça, 2011.

Recebido em 27 de setembro de 2017. Aprovado em 04 de dezembro de 2017. 